\title{
Supporting Information \\ Solvent-Additive Coordination Effect on Lead-Iodide Precursor for Enlarging Grain Size of Perovskite Film
}

Hyungwoo Kim ${ }^{\$, \dagger}$, Ji Hoon Seo ${ }^{\$,+,+}$, Srikanta Palei ${ }^{\dagger}$, and Kwanyong Seo ${ }^{*},+$

$\uparrow$ School of Energy and Chemical Engineering, Ulsan National Institute of Science and

Technology (UNIST), Ulsan 44919, Republic of Korea

$\$$ New and Renewable Energy Laboratory, Korea Electric Power Research Institute (KEPRI),

Daejeon 34056, Republic of Korea

H.K. and J.H.S. contributed equally to this work.

*Corresponding author: Kwanyong Seo

Email: kseo@unist.ac.kr 


\section{- EXPERIMENTAL SECTION}

Solution Preparation. To fabricate the perovskite, a $\mathrm{PbI}_{2}$ precursor solution and an organoammonium halide solution were prepared separately. In the first step, $1.3 \mathrm{M}$ of $\mathrm{PbI}_{2}$ precursor solution was prepared by dissolving $\mathrm{PbI}_{2}$ powder (TCI Co.) in $N, N$-dimethylformamide (Sigma-Aldrich) and stirred on a hot-plate at $85{ }^{\circ} \mathrm{C}$ for $1 \mathrm{~h}$. As solvent additives, $50 \mu \mathrm{L}$ of acetonitrile (ACN), $\gamma$-butyrolactone (GBL), methanol (ME), tetrahydrofuran (THF), and dimethyl sulfide (DMS) were prepared. Each solvent additive was mixed separately in $950 \mu \mathrm{L}$ of 1.3 $\mathrm{M} \mathrm{PbI}_{2}$ precursor solution before being spin-coated. The second step solution, $0.5 \mathrm{M}$ of organo-ammonium halide solution, was prepared by dissolving formamidinium iodide (FAI), methylammonium bromide (MABr), and methylammonium chloride (MACl) with a molar ratio of 71:11:18 in 2-propanol. As an electron transport material, an $\mathrm{SnO}_{2}$ solution was prepared by diluting $15 \%$ of $\mathrm{SnO}_{2}$ (Alfa Aesar) solution in deionized water with a volume ratio of 2:11. As a hole transport material, a Spiro-MeOTAD solution was fabricated by dissolving $72.3 \mathrm{mg}$ of $2,2^{\prime}, 7,7^{\prime}$-tetrakis[N,N-di(4-methoxyphenyl)amino]-9,9'-spirobufluorene (SpiroMeOTAD, Jilin OLED Material Tech) in $1 \mathrm{~mL}$ of chlorobenzene (Sigma-Aldrich) and adding $28.8 \mu \mathrm{L}$ of 4 -tert-butylpridine (Sigma-Aldrich), and $17.5 \mu \mathrm{L}$ of $0.5 \quad \mathrm{M}$ bis(trifluoromethane)sulfonimide lithium solution (Li-TFSI, dissolved in acetonitrile, SigmaAldrich). For the electron transport material of electron-only devices, a [6,6] phenyl-C61butyric acid methyl ester $\left(\mathrm{PC}_{61} \mathrm{BM}\right)$ solution was fabricated by dissolving $20 \mathrm{mg}$ of $\mathrm{PC}_{61} \mathrm{BM}$ powder in $1 \mathrm{ml}$ of chlorobenzene.

Film Fabrication. To fabricate the $\mathrm{PbI}_{2}$ film, the first step was performed in the dry box (RH of $20 \% / 25^{\circ} \mathrm{C}$ ). Each $1.3 \mathrm{M}$ of the $\mathrm{PbI}_{2}$ solution with the solvent additives was spin-coated on a $2.5 \mathrm{~cm} \times 2.5 \mathrm{~cm}$ bare glass at $2000 \mathrm{rpm}$ for $15 \mathrm{~s}$. To fabricate the perovskite film, the first 
and second steps were performed sequentially in a dry box. Each $1.3 \mathrm{M}$ of the $\mathrm{PbI}_{2}$ solution with solvent additives was spin-coated on the glass at $2000 \mathrm{rpm}$ for $15 \mathrm{~s}$. Subsequently, the organo-ammonium halide solution was spin-coated at $2000 \mathrm{rpm}$ for $15 \mathrm{~s}$. After the consecutive spin-coating process, the samples were annealed on the hot plate at $150{ }^{\circ} \mathrm{C}$ for $20 \mathrm{~min}$.

Fabrication of Perovskite Solar Cells. As the substrates, $2.5 \mathrm{~cm} \times 2.5 \mathrm{~cm} \mathrm{ITO/glass} \mathrm{(AMG}$ tech) substrates were cleaned in acetone and isopropanol under sonication for $10 \mathrm{~min}$. The substrates were kept in a dry oven at $80{ }^{\circ} \mathrm{C}$ overnight. The $\mathrm{SnO}_{2}$ solution was deposited by spin-coating at $3000 \mathrm{rpm}$ for $30 \mathrm{~s}$ on the substrates. After $\mathrm{SnO}_{2}$ coating, the samples were annealed on the hot plate at $150{ }^{\circ} \mathrm{C}$ for $30 \mathrm{~min}$. After annealing, the perovskite was fabricated onto a $\mathrm{SnO}_{2} / \mathrm{ITO} /$ glass substrate using the aforementioned two-step spin-coating process. The Spiro-MeOTAD solution was spin-coated on perovskite/ $\mathrm{SnO}_{2} / \mathrm{ITO} /$ glass substrates at 4000 rpm for $40 \mathrm{~s}$. Finally, a $100 \mathrm{~nm}$-thick Au counter electrode was deposited using the thermal evaporator.

Fabrication of Electron-only Devices. As the substrates, $2.5 \mathrm{~cm} \times 2.5 \mathrm{~cm} \mathrm{ITO/glass} \mathrm{(AMG}$ tech) substrates were cleaned in acetone and isopropanol under sonication for $10 \mathrm{~min}$. The substrates were kept in a dry oven at $80{ }^{\circ} \mathrm{C}$ overnight. The perovskite/SnO2/ITO/glass layers are fabricated to the same process to that of the perovskite solar cells. On the perovskite layers $\mathrm{PC}_{61} \mathrm{BM}$ solution was deposited at $1000 \mathrm{rpm}$ for 45 s. Finally, a $100 \mathrm{~nm}$-thick $\mathrm{Au}$ counter electrode was deposited using the thermal evaporator.

Morphology Analysis. The surface morphologies of $\mathrm{PbI}_{2}$ and perovskite films were characterized by field emission scanning electron microscopy (FE-SEM, Hitachi S-4800) under an accelerating voltage of $10.0 \mathrm{kV}$ and a beam intensity of $10 \mu \mathrm{A}$. The captured FE-SEM 
images were analyzed using Image J software. The FE-SEM images were treated using the edge find algorithm, and the grain boundaries were sharpened by enhancing the contrast. Subsequently, the images were binarized to be white (RGB 255, 255, 255) or black (RGB 0,0, 0). After binarization, the white dots were removed using the despeckled algorithm, and then, the opened grain boundaries were closed using the watershed algorithm. The Atomic-force microscopy (AFM) data of the perovskite fims was obtained using the atomic force microscope (Dimension ICON, Bruker Nano Surface). The surface roughness of the film with a size of 5 $\mu \mathrm{m} \times 5 \mu \mathrm{m}$ was measured by the atomic force microscope.

Analysis of Optical Properties. The photoluminescence (PL) spectra of the perovskite films were obtained using the fluorometer (Varian, Cary Eclipse). The wavelength of the excitation beam pulse was $530 \mathrm{~nm}$. The PL emission was scanned at an interval of $1 \mathrm{~nm}$ at $600 \mathrm{~nm} / \mathrm{min}$. The Time-resolved PL (TRPL) decay was measured using a time-domain fluorometer (ISS Inc., Chronos $\mathrm{BH}$ ) with an excitation light pulse generated using a picosecond light pulser (Hamamatsu, C10196). The incident excitation beam wavelength was $530 \mathrm{~nm}$. The PL quantum-yield (PLQY) was obtained using a spectrofluorometer (Jasco International, FP$8500 \mathrm{ST}$ ) with an excitation wavelength of $530 \mathrm{~nm}$ and a scan rate of $500 \mathrm{~nm} / \mathrm{min}$. The X-ray diffraction (XRD) measurements of the perovskite films were carried out using a X-ray Diffractometer (D8 Advance, Bruker AXS). The range of $2 \theta$ is $10^{\circ}$ to $80^{\circ}$ with $0.02^{\circ}$ of step size and $0.45^{\circ} / \mathrm{min}$ of scan speed using $\mathrm{Cu} \mathrm{K} \alpha$ target. Fourier-transform infrared spectroscopy (FT-IR) spectra of the $\mathrm{PbI}_{2}$ films using the solvent additives was obtained by a spectrometer (670 / 620, Varian). The scans were performed in the spectra range from $4000-650 \mathrm{~cm}^{-1}$ of wavenumber at a spectral resolution of $0.075 \mathrm{~cm}^{-1}$. 
Device Characterization. The photovoltaic properties of the perovskite solar cells were measured using a solar simulator (Class AAA, Oriel Sol3A, Newport) under AM 1.5G (100 $\mathrm{mW} / \mathrm{cm}^{2}$ ) illumination. The incident light flux of the solar simulator was measured using a calibrated power meter with a double-check by measuring the photovoltaic properties using a National Renewable Energy Laboratory (NREL)-calibrated solar cell (PV Measurements, Inc.). The voltage scan range was -0.2 to $1.2 \mathrm{~V}$ with a scan rate of $400 \mathrm{mV} / \mathrm{s}$ at room temperature in ambient air atmosphere. The aperture area of the perovskite solar cells was $0.0425 \mathrm{~cm}^{2}$ with a black shadow mask. The EQE spectra were obtained using a Xenon lamp through a wavelength range of $300-900 \mathrm{~nm}$ at a chopping frequency of $10 \mathrm{~Hz}$. The electrochemical impedance spectrometry (EIS) spectra were measured using an electrochemical analysis system (combined potentiostate 1287A, Impedance/Gain-phase analyzer 1260A, Solartron Analytical, AMETEK, Inc.). On each electrode of the perovskite solar cells, an applied voltage of $0.9 \mathrm{~V}$ with an $\mathrm{AC}$ signal of $0.2 \mathrm{mV}$ was induced under dark conditions. The impedance was scanned by sweeping the frequency from $1 \mathrm{MHz}$ to $100 \mathrm{mHz}$. All the obtained Nyquist plots were fitted using ZView software (Scribner Associates, Inc.) with suitable equivalent circuits. The space charge-limited current (SCLC) was measured using Power source meter (2400 Source meter, Keithly) The voltage scan range was -0.5 to $2.8 \mathrm{~V}$ with a scan rate of $10 \mathrm{mV} / \mathrm{s}$ at room temperature in ambient air atmosphere. 
2-Step process

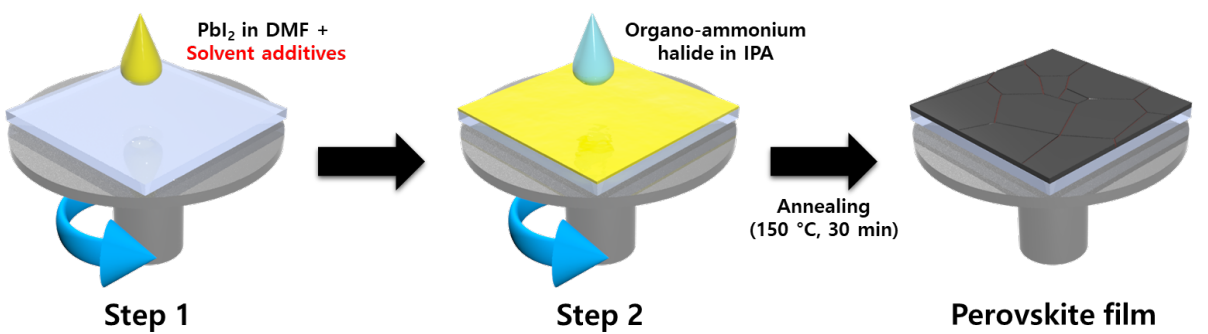

Scheme S1. Schematic of the perovskite film fabrication through the two-step process 
Table S1. Full width at half maximum (FWHM) of the perovskite (110) peak of XRD spectra shown in Figure S4.

\begin{tabular}{|l|l|}
\hline Perovskite films & FWHM of $(110)$ peak $\left(^{\circ}\right)$ \\
\hline with ACN & 0.1940 \\
\hline with GBL & 0.1832 \\
\hline with ME & 0.1318 \\
\hline with THF & 0.1159 \\
\hline with DMS & 0.1022 \\
\hline
\end{tabular}


Table S2. Trap-filled voltage (V) and charge trap density of the space charge-limited current (SCLC) measurements shown in Figure S5.

\begin{tabular}{|l|l|l|}
\hline Electron-only devices & \multicolumn{1}{|c|}{ Trap-filled voltage (V) } & Charge trap density $\left(\mathbf{c m}^{\mathbf{3}}\right)$ \\
\hline with ACN & 1.60 & $1.014 \times 10^{16}$ \\
\hline with GBL & 1.53 & $9.703 \times 10^{15}$ \\
\hline with ME & 1.46 & $9.259 \times 10^{15}$ \\
\hline with THF & 1.32 & $8.371 \times 10^{15}$ \\
\hline with DMS & 1.23 & $7.800 \times 10^{15}$ \\
\hline
\end{tabular}


Table S3. Detailed photovoltaic parameters summarized in Table 2.

\begin{tabular}{|l|l|l|l|l|}
\hline ACN & \multicolumn{1}{|c|}{\begin{tabular}{c}
\multicolumn{1}{c|}{$\mathbf{V}_{\text {oc }}$} \\
$(\mathbf{m V})$
\end{tabular}} & \multicolumn{1}{c|}{$\begin{array}{c}\text { J } \\
\left(\mathbf{m A} / \mathbf{c m}^{2}\right)\end{array}$} & $\begin{array}{c}\text { FF } \\
(\mathbf{\%})\end{array}$ & $\begin{array}{c}\text { PCE } \\
(\%)\end{array}$ \\
\hline Sample 1 & 916 & 23.6 & 74.5 & 16.1 \\
\hline Sample 2 & 997.1 & 23.4 & 72.9 & 17 \\
\hline Sample 3 & 976.8 & 23.4 & 73.3 & 16.8 \\
\hline Sample 4 & 1020 & 23.5 & 68.8 & 16.8 \\
\hline Sample 5 (Best) & 1020 & 23.5 & 72.3 & 17.3 \\
\hline Sample 6 & 916 & 23.5 & 75.2 & 16.2 \\
\hline Sample 7 & 1040 & 23.1 & 64.2 & 15.7 \\
\hline Sample 8 & 916 & 23.4 & 71.5 & 15.3 \\
\hline Sample 9 & 1020 & 23.6 & 67 & 16.1 \\
\hline Sample 10 & 936.3 & 23.5 & 73.6 & 16.2 \\
\hline Average & 975.82 & 23.45 & 71.33 & 16.35 \\
\hline
\end{tabular}

\begin{tabular}{|l|l|l|l|l|}
\hline GBL & \multicolumn{1}{|c|}{$\begin{array}{c}\mathbf{V}_{\text {oc }} \\
(\mathbf{m V})\end{array}$} & $\begin{array}{c}\mathbf{J}_{\text {sc }} \\
\left(\mathbf{m A} / \mathbf{c m}^{2}\right)\end{array}$ & $\begin{array}{c}\text { FF } \\
(\mathbf{\%})\end{array}$ & \multicolumn{1}{c|}{$\begin{array}{c}\text { PCE } \\
(\%)\end{array}$} \\
\hline Sample 1 & 1020 & 23.3 & 70.8 & 17.1 \\
\hline Sample 2 & 1040 & 23.6 & 73.6 & 18 \\
\hline Sample 3 & 976.8 & 23.2 & 74.2 & 16.8 \\
\hline Sample 4 & 997.1 & 23.6 & 75.7 & 17.8 \\
\hline Sample 5 & 1020 & 23.6 & 74.8 & 18 \\
\hline Sample 6 & 1020 & 23.6 & 75.3 & 18.1 \\
\hline Sample 7 (Best) & 1020 & 23.6 & 75.9 & 18.2 \\
\hline Sample 8 & 1040 & 23.4 & 71.6 & 17.7 \\
\hline Sample 9 & 1040 & 23.7 & 72.9 & 17.9 \\
\hline Sample 10 & 1040 & 23.5 & 74.1 & 18.1 \\
\hline Average & 1021.39 & 23.51 & 73.89 & 17.77 \\
\hline
\end{tabular}

\begin{tabular}{|l|l|l|l|l|}
\hline ME & \multicolumn{1}{|c|}{$\begin{array}{c}\mathbf{V}_{\text {oc }} \\
(\mathbf{m V})\end{array}$} & \multicolumn{1}{c|}{$\begin{array}{c}\mathbf{J}_{\mathbf{s c}} \\
\left(\mathbf{m A} / \mathbf{c m}^{2}\right)\end{array}$} & $\begin{array}{c}\text { FF } \\
(\mathbf{\%})\end{array}$ & $\begin{array}{c}\text { PCE } \\
(\mathbf{\%})\end{array}$ \\
\hline Sample 1 & 1040 & 23.7 & 74.8 & 18.4 \\
\hline Sample 2 & 1060 & 23.5 & 75.9 & 19.3 \\
\hline Sample 3 & 1060 & 23.7 & 76.1 & 19.5 \\
\hline Sample 4 & 1080 & 23.4 & 74.3 & 18.7 \\
\hline Sample 5 & 1060 & 23.8 & 76.9 & 19.4 \\
\hline Sample 6 & 1060 & 23.5 & 74.5 & 18.9 \\
\hline Sample 7 & 1060 & 23.6 & 74.4 & 18.9 \\
\hline Sample 8 (Best) & 1080 & 23.6 & 77.8 & 19.8 \\
\hline Sample 9 & 1060 & 23.1 & 74.4 & 18.2 \\
\hline Sample 10 & 1060 & 23.5 & 76 & 19.3 \\
\hline Average & 1062 & 23.54 & 75.51 & 19.04 \\
\hline
\end{tabular}




\begin{tabular}{|l|l|l|l|l|}
\hline THF & \multicolumn{1}{|c|}{$\begin{array}{c}\mathbf{V}_{\text {oc }} \\
(\mathbf{m V})\end{array}$} & $\begin{array}{c}\mathbf{J}_{\text {sc }} \\
\left(\mathbf{m A} / \mathbf{c m}^{2}\right)\end{array}$ & $\begin{array}{c}\text { FF } \\
(\mathbf{\%})\end{array}$ & \multicolumn{1}{c|}{$\begin{array}{c}\text { PCE } \\
(\%)\end{array}$} \\
\hline Sample 1 & 1060 & 23.8 & 73.8 & 19.3 \\
\hline Sample 2 & 1080 & 23.4 & 77.8 & 19.6 \\
\hline Sample 3 & 1060 & 23.9 & 79 & 20 \\
\hline Sample 4 & 1060 & 23.8 & 74.5 & 18.7 \\
\hline Sample 5 & 1060 & 23.8 & 73.7 & 18.9 \\
\hline Sample 6 & 1080 & 23.8 & 74.8 & 19.2 \\
\hline Sample 7 & 1060 & 23.7 & 77.4 & 19.8 \\
\hline Sample 8 (Best) & 1080 & 23.8 & 78.2 & 20.4 \\
\hline Sample 9 & 1080 & 23.4 & 79.7 & 20.1 \\
\hline Sample 10 & 1060 & 23.9 & 76.1 & 19.3 \\
\hline Average & 1068 & 23.73 & 76.5 & 19.53 \\
\hline
\end{tabular}

\begin{tabular}{|l|l|l|l|l|}
\hline DMS & \multicolumn{1}{|c|}{$\begin{array}{c}\mathbf{V}_{\text {oc }} \\
(\mathbf{m V})\end{array}$} & \multicolumn{1}{c|}{$\begin{array}{c}\mathbf{J}_{\mathbf{s c}} \\
\left(\mathbf{m A} / \mathbf{c m}^{2}\right)\end{array}$} & $\begin{array}{c}\text { FF } \\
(\%)\end{array}$ & $\begin{array}{c}\text { PCE } \\
(\%)\end{array}$ \\
\hline Sample 1 & 1020 & 24.1 & 80.3 & 19.7 \\
\hline Sample 2 & 1040 & 24.1 & 79.2 & 20.2 \\
\hline Sample 3 & 1100 & 23.4 & 79.2 & 20.4 \\
\hline Sample 4 & 1080 & 24 & 78 & 19.8 \\
\hline Sample 5 (Best) & 1100 & 24 & 80.2 & 21.2 \\
\hline Sample 6 & 1080 & 24.1 & 81.2 & 21.1 \\
\hline Sample 7 & 1080 & 24 & 80.7 & 20.9 \\
\hline Sample 8 & 1060 & 24.1 & 79.9 & 20.8 \\
\hline Sample 9 & 1060 & 23.8 & 76.1 & 19.2 \\
\hline Sample 10 & 1060 & 23.7 & 77.4 & 19.4 \\
\hline Average & 1068 & 23.93 & 79.22 & 20.27 \\
\hline
\end{tabular}




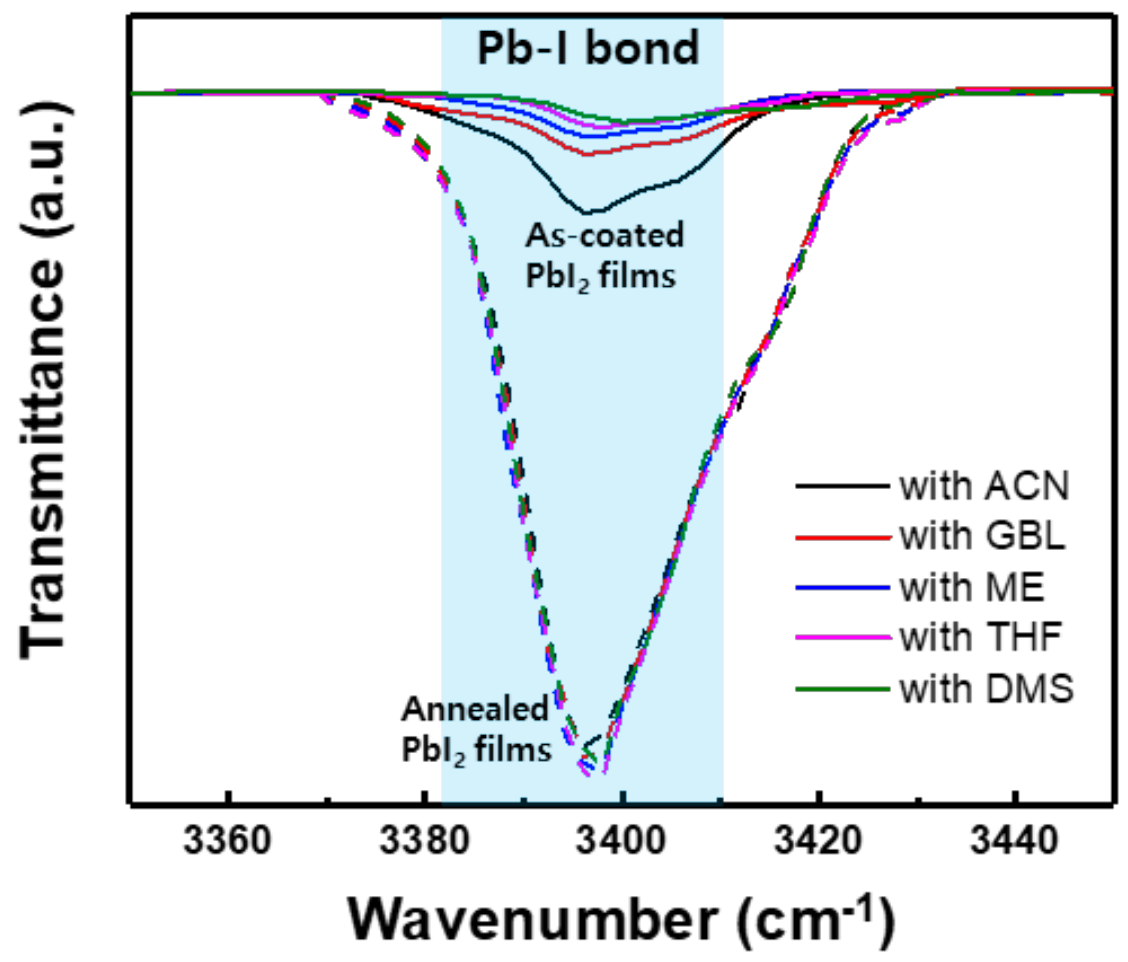

Figure S1. Fourier-transform infrared spectroscopy (FT-IR) spectra of the $\mathrm{PbI}_{2}$ films using the solvent additives (solid line: as-coated; dashed line: annealed $\mathrm{PbI}_{2}$ films) 


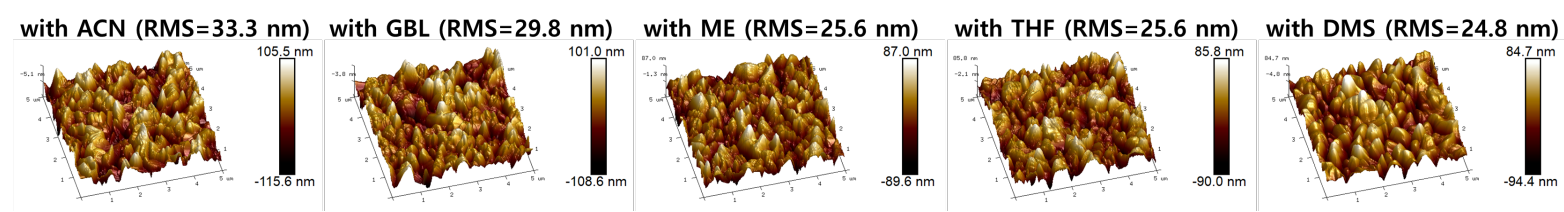

Figure S2. Atomic-force microscopy (AFM) image with 3D mapping of the perovskite films using the solvent additives. 

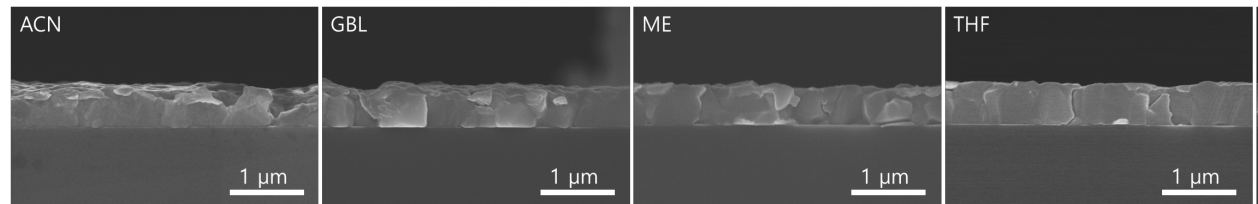

Figure S3. Field-emission scanning electron microscopy (FE-SEM) images of the perovskite films obtained using different solvent additives (cross-section view). 


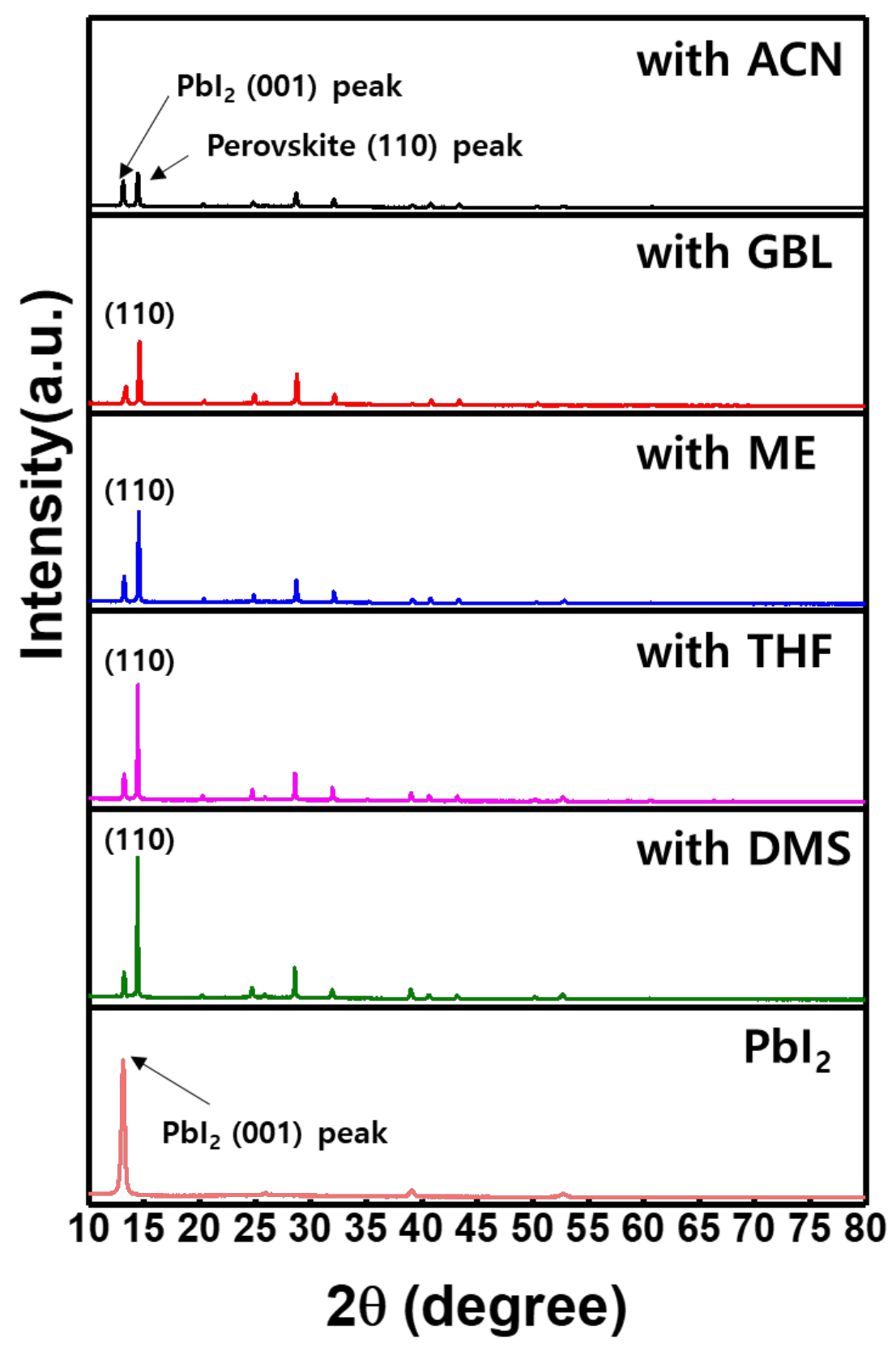

Figure S4. X-ray diffraction (XRD) spectra of the perovskite films obtained using the solvent additives and the $\mathrm{PbI}_{2}$ film. 


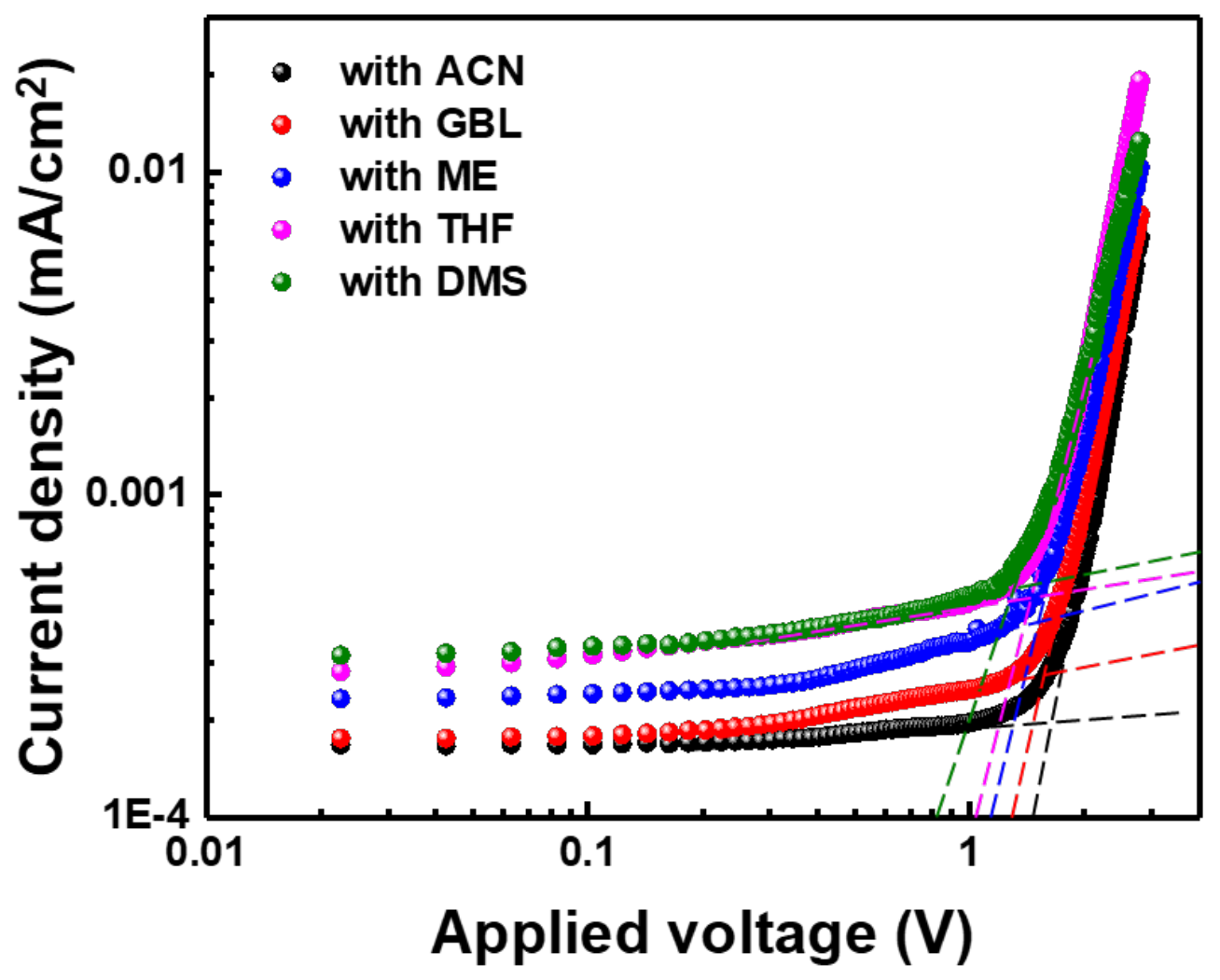

Figure S5. Space charge-limited current (SCLC) measurements for the electron-only devices obtained using different solvent additives. 


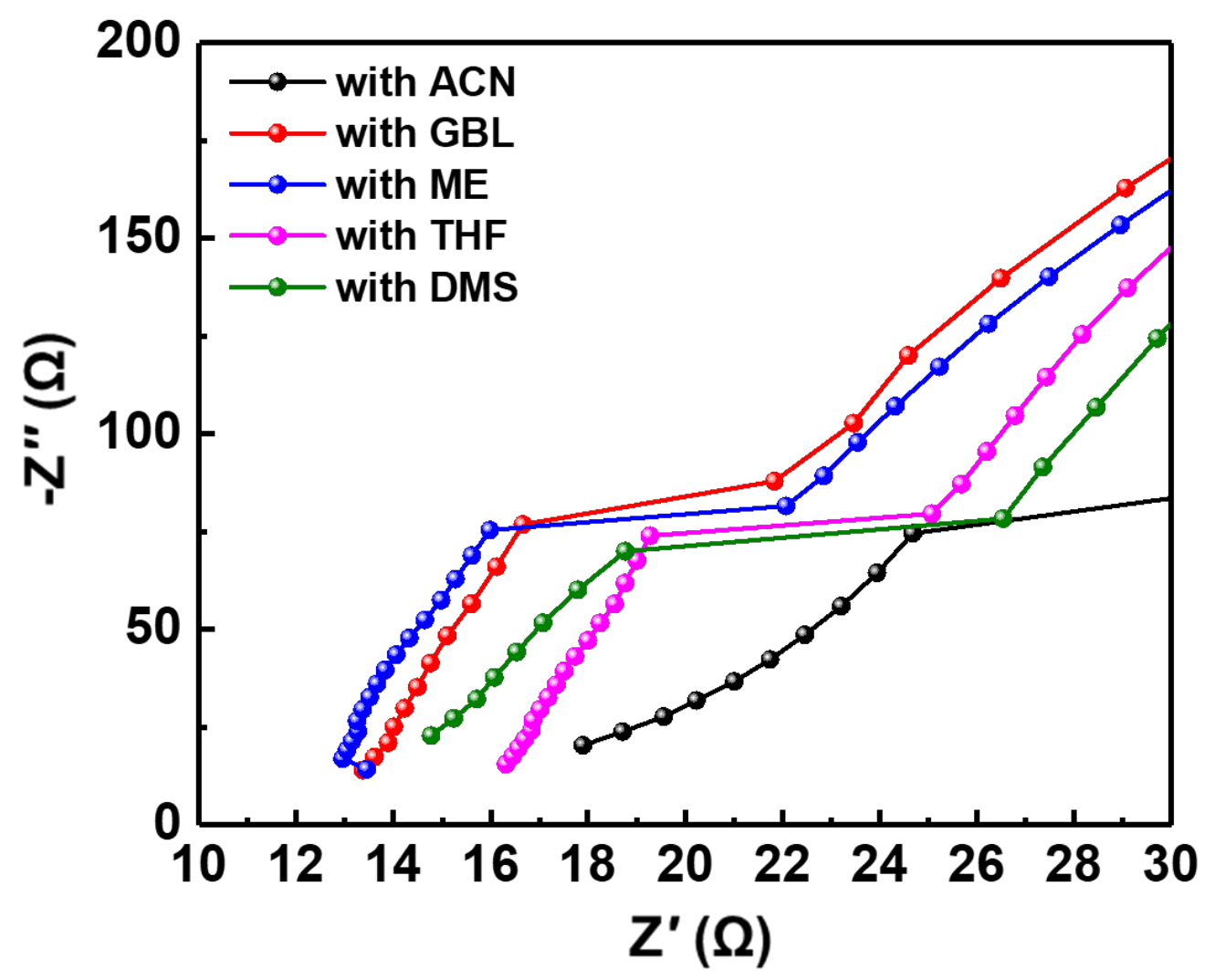

Figure S6. Magnified Nyquist plot of the perovskite solar cells in the high-frequency region. 


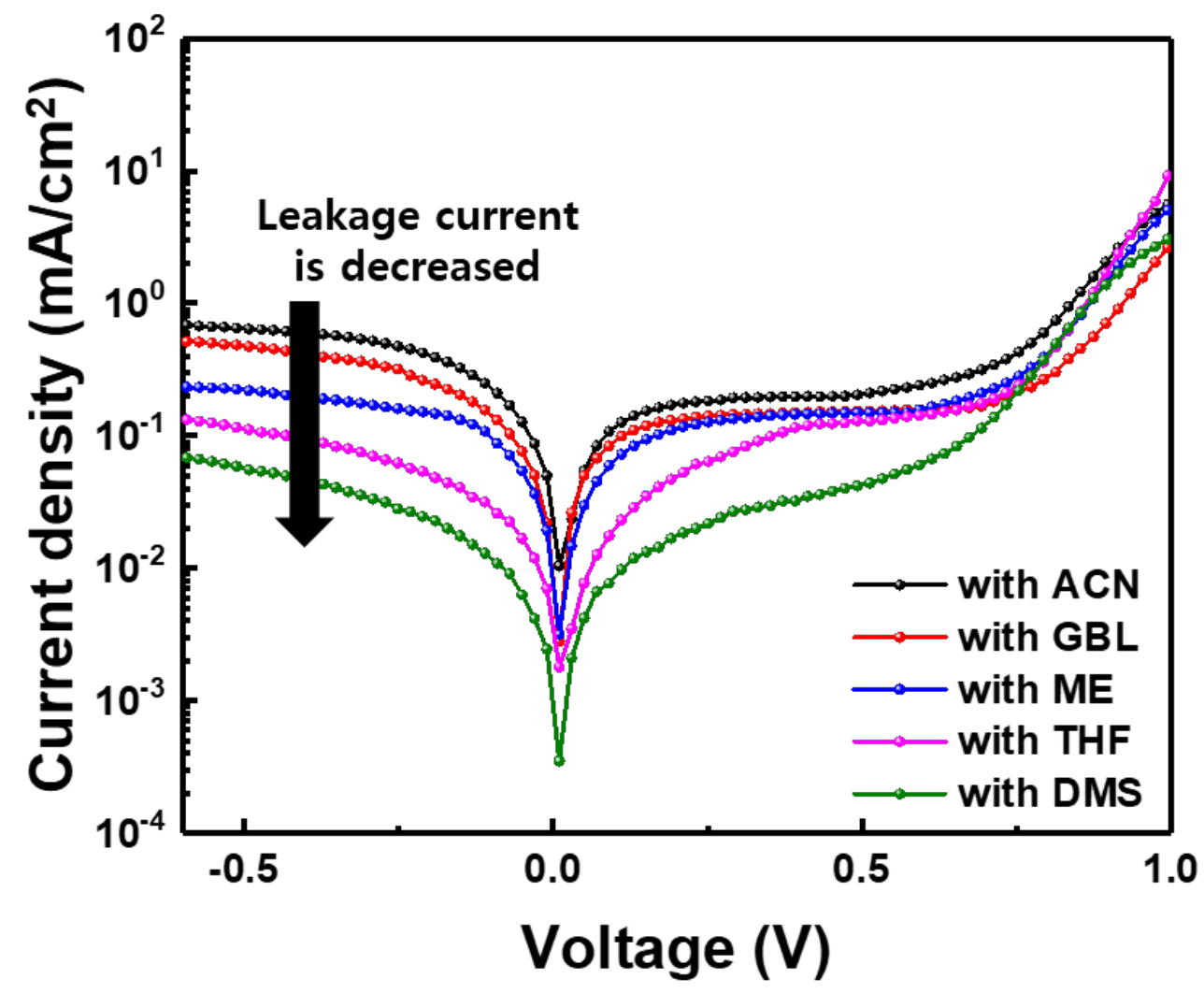

Figure S7. Dark J-V curve for the perovskite solar cells obtained using different solvent additives. 